\title{
A prática da não-retenção escolar na narrativa de professores do ensino fundamental: dificuldades e avanços na busca do sucesso escolar.
}

\author{
Dília Maria Andrade Glória \\ Universidade Federal de Minas Gerais \\ Leila de Alvarenga Mafra \\ Pontifícia Universidade Católica de Minas Gerais
}

\section{Resumo}

Este estudo descreve e analisa as percepções de professores sobre a prática da não-retenção escolar que busca possibilitar a alunos de camadas populares uma sobrevivência escolar mais prolongada. Para tanto, definiu-se como locus da pesquisa uma escola fundamental da Rede Municipal de Educação de Belo Horizonte, que, desde 1995, assumiu o projeto político-pedagógico Escola Plural. A partir dessa reforma, mudanças radicais foram introduzidas na organização pedagógica das escolas e no trabalho docente objetivando construir uma escola mais includente e democrática. Numa abordagem qualitativa como procedimento central de investigação, foram realizadas entrevistas semiestruturadas com os professores, no sentido de configurar as práticas pedagógicas construídas por esses atores e apreender alterações nos aspectos relativos aos processos de escolarização dos educandos a partir da adoção dos ciclos de formação e da eliminação dos mecanismos de reprovação escolar. A análise do material discursivo, obtido com a realização das entrevistas, foi feita pelo método de análise de conteúdo. A conclusão é de que o princípio da não-retenção, no âmbito da escola pesquisada, não consegue desfazer, por si mesma, os nós imbricados no sistema de ensino e reverter o quadro de exclusão que ainda persiste. Sem que os processos de ensino, as práticas pedagógicas e as estratégias escolares se reformulem para adquirirem contornos menos punitivos, seletivos e excludentes, o avanço certamente se mostrará limitado a uma escola que exclui menos, mas que continua excluindo.

\section{Palavras-chave}

Não-retenção escolar - Professores - Sucesso escolar. 


\title{
The practice of assessment by learning cycles in the narrative of primary school teachers: difficulties and advances in the search for school success
}

\author{
Dília Maria Andrade Glória \\ Universidade Federal de Minas Gerais \\ Leila de Alvarenga Mafra \\ Pontifícia Universidade Católica de Minas Gerais
}

\author{
Contact: \\ Dília Maria Andrade Glória \\ Escola Fundamental do Centro \\ Pedagógico da UFMG \\ Av. Antônio Carlos, 6627 \\ 31270-010-Belo Horizonte - MG \\ e-mail:dilia@dedalus.Icc.ufmg.br
}

\begin{abstract}
The present study describes and analyzes the perceptions of teachers about the practice of assessment by learning cycles, which seeks to give students from the lower social classes an extended "survival" in school. The chosen locus for the research was a primary school from the Belo Horizonte Public School System, which since 1995 has implemented the Escola Plural ("Plural School") political-pedagogical project. From such reform, radical changes were introduced to the pedagogical organization of schools and to the work of teachers with a view to build a more socially inclusive and democratic school. Taking a qualitative approach as the central procedure for this investigation, semi-structured interviews were conducted with teachers with the purpose of picturing the pedagogical practices constructed by these agents, as well as apprehending changes in the aspects related to the schooling process of pupils since the adoption of learning cycles and the elimination of mechanisms of school failure. The analysis of the discursive material obtained from the interviews was made through the method of Content Analysis. The conclusion is that within the school studied here the principle of automatic promotion, per se, cannot untie the intricate knots of the school system to overturn the picture of exclusion that still persists. Without reforming the teaching processes, the pedagogical practices and school strategies, to give them less punitive, selective and excluding contours the advances will certainly be limited to a school that excludes less but still excludes.
\end{abstract}

\section{Keywords}

Automatic promotion - Teachers - School success. 
Neste artigo, descrevem-se e analisam-se dados coletados sobre as percepções, expectativas e estratégias pedagógicas construídas por professores de uma escola fundamental a partir da adoção do princípio da não-retenção. Esse princípio, adotado para assegurar uma sobrevivência escolar mais prolongada dos alunos de camadas populares, tem proporcionado aos professores uma prática pedagógica singular, que exige esforços individuais e coletivos e novas relações com os alunos e seus familiares bem como com os demais atores escolares. Nesse processo, expectativas, atitudes, ações e sentimentos consensuais, conflitivos e contraditórios são desencadeados, trazendo à tona um cenário em desconstrução e reconstrução permanentes.

0 princípio da não-retenção escolar, admitido como uma política educacional pública avançada por algumas administrações municipais nos anos 1990, fundamenta-se nas concepções liberais que defendem a educação como direito de todos os cidadãos, pensamento oriundo da Revolução Francesa, no século XVIII (Horta, 1998). Nesse momento, a escola pública é concebida para propiciar a democratização das oportunidades educacionais mediante o acesso a todos os cidadãos à escola. No Brasil, entretanto, os direitos sociais têm sido tardiamente assinalados nas Constituições Federais (Cury; Horta; Fávero, 1996), e a escola pública não chegou a se implantar no país nos termos propostos pelo movimento iluminista. Para Cury (2000, p. 583), “a importância da educação para o processo de construção da democracia no país sempre foi muito enfatizada, mas não necessariamente efetivada”. Assim, um contingente expressivo de sujeitos vem sendo excluído do processo de escolarização. No entanto, com a expansão do ensino público brasileiro, a preocupação em garantir o acesso à escola é central nas políticas públicas nacionais $\mathrm{e}$ vai progressivamente cedendo espaço à questão da permanência no sistema escolar (Teixeira, 1969; Romanelli, 1998), sobretudo dos alunos oriundos das camadas populares. A inquietação com a situação educacional dos grupos sociais menos favorecidos se justifica, uma vez que é fato pesquisado e comprovado - o tempo de permanência na escola relaciona-se à origem social do aluno (Forquin, 1995), e as vantagens e desvantagens educacionais são cumulativas, afetando os destinos escolares dos alunos e suas chances fora da escola (Bourdieu, 1998).

Especialmente a partir dos anos 1970, a questão da permanência dos alunos na escola torna-se uma preocupação social premente, por estar a escola pública alicerçada num eficiente sistema de reprovação caracterizado pelo uso de diversos mecanismos seletivos, sobressaindo-se, dentre esses, os exames, os testes de conhecimento, testes psicológicos, a organização curricular, etc. Assim sendo, embora as crianças tenham acesso à escola, os processos seletivos no seu interior têm dificultado a trajetória regular dos alunos e ampliado o número de repetências, recuperações e evasões. No Brasil, tais dificuldades têm gerado o fenômeno da defasagem série/idade, sobretudo no ensino fundamental, o que, por sua vez, reduz as possibilidades de maior democratização do sistema escolar também nos níveis de ensino médio e superior. As desigualdades educacionais são, assim, bastante ampliadas, no sistema de ensino como um todo.

Ressalte-se que os temas da evasão, reprovação e repetência escolares não são novos na literatura educacional brasileira. Na década de 1950, Anísio Teixeira (1994) já discutia seus altos índices, afirmando o direito de todos a uma educação escolar pública e a importância de medidas governamentais no sentido de democratizar as oportunidades educacionais no Brasil. Todavia, na década de 1980 , tais temas se tornam o assunto por excelência no meio acadêmico, quando autores como Maria Helena Patto, Terezinha Carraher e Analúcia Schliemann, Magda Soares, Sérgio Ribeiro e outros discutiram exaustivamente suas causas e conseqüências. Nesse período, o fracasso escolar passa a ser entendido como o fracasso da escola. São muitos e diversos os questionamentos relativos, 
principalmente, à precariedade do ensino oferecido às classes populares em termos quantitativos e qualitativos.

Nos anos 1980, tem-se, pois, claramente configurada e enfaticamente questionada uma verdadeira cultura do fracasso escolar, alicerçada, sobretudo, numa prática indiscriminada de reprovações. Há também a introdução de mudanças na política educacional por parte de grupos mais progressistas em alguns estados, que, além de democratizarem o acesso à escola, visam ainda à qualidade do ensino. Algumas mudanças enfocam o aspecto pedagógico, ao passo que outras são de caráter mais assistencialista (Silva et al., 1993). Na rede pública do estado de São Paulo, foi instituído, em 1983, o Ciclo Básico,

programa que visava ampliar o período de alfabetização dos alunos das duas primeiras séries do $1^{\circ}$ grau (atingindo cerca de 1 milhão de crianças), de modo a diminuir a reprovação nas séries iniciais do ensino fundamental. (Silva et al., 1993, p. 9)

No mesmo período, medida semelhante é adotada em Minas Gerais e, posteriormente, em outros estados, como o Paraná. São também implantados: a Jornada Única de Trabalho Docente e Discente, em 1988, em São Paulo, com o propósito de ampliar o tempo de permanência do professor e do aluno nos dois primeiros anos da escola; os Centros Integrados de Educação Pública - CIEPs -, no estado do Rio de Janeiro, como modelos de escolas públicas de tempo integral voltadas para a população menos privilegiada social e economicamente; o Programa de Formação Integral da Criança - Profic -, no final de 1986, em São Paulo, com o objetivo de atender os menores numa perspectiva protecionista, especialmente os de baixa renda; e os Centros Integrados de Atendimento à Criança - $\mathrm{ClACs}-$, em 1991, pelo governo federal, que combinam características dos CIEPs e do Profic. Todavia, essas medidas não foram suficientes para sanar o quadro do fracasso escolar configurado sob a forma de altos índices de reprovações, repetências e evasões. Esse insucesso parece ser decorrente de uma conjugação de fatores: falta de recursos; instabilidade política; ambigüidade na relação dos dirigentes com a população, que bem se exemplifica no imediatismo demagógico; e, ainda, pela ausência de mecanismos de avaliação e informação da sociedade civil como "indispensável no controle, fiscalização e cobrança das ações governamentais" (Silva et al., 1993, p. 14). Assim,

passados dez anos de abertura democrática, incentivo à participação popular e implementação de projetos pedagógicos por governos estaduais eleitos pelo voto popular, os dados educacionais retratam uma situação de estagnação, ou até mesmo de retrocesso, no atendimento quantitativo em todos os níveis de ensino. 0 sistema educacional continua altamente seletivo, concentrando a maioria absoluta de seus alunos nos níveis elementares. (Silva et al., 1993, p. 12)

Todo esse quadro de denúncias e críticas ao sistema escolar irá desencadear, basicamente na década de 1990, uma discussão e revisão sobre a política educacional brasileira que, segundo Patto (1988, p. 73), "vem, em relação aos seus problemas fundamentais, se debatendo no beco sem saída de concepções equivocadas a respeito da natureza dos problemas e de sua solução". A proposta que se delineia é a de substituição da cultura do fracasso escolar por uma cultura do sucesso escolar, cujo eixo irá centrar-se na estratégia da nãoretenção escolar. 0 discurso da mudança pauta-se, entre outros pontos, pela "necessidade de se assumir o princípio de eqüidade na educação escolar e da escola enquanto um lugar de progresso para a criança, considerando-se o sucesso dessa criança como a meta mais valiosa" (Gatti, 1993, p. 6). 0 sucesso não deve ser pensado em termos do não-fracasso, o que significaria apenas um indicador de inclusão social. Não deve bastar que os alunos concluam o ensino fundamental, conforme previsto 
na Constituição Brasileira de 1988, como um direito. É preciso ir além do básico, estendendo-se a discussão do sucesso à qualidade da escolaridade: "Passa-se assim de um conceito bancário - quantos dentro e quantos fora para um conceito qualitativo sobre as aquisições, de quem está dentro e de quem está fora, para alcançar uma vida digna como brasileiro" (Sposati, 2000, p. 25).

Assim, ao considerar que o sistema de reprovação escolar implica perdas significativas, tanto em termos de recursos humanos como materiais e financeiros, nos anos 1990, algumas administrações públicas, especialmente no âmbito municipal, passaram a adotar projetos político-pedagógicos inovadores, que introduzem o princípio da progressão continuada na escolarização dos alunos, com a adoção do sistema de não-retenção escolar. Essas propostas, alicerçadas na gestão democrática da escola, redimensionam o espaço, o tempo e a organização do trabalho escolar com o objetivo de construir uma nova lógica capaz de garantir a todos os alunos o direito a uma aprendizagem efetiva, com vistas à cidadania. Para tal, propõe-se eliminar os mecanismos e procedimentos escolares que tradicionalmente produzem a exclusão das camadas populares da escola. Entre esses mecanismos, é ressaltada, na maioria desses programas, o fim da reprovação e da repetência por meio dos ciclos de formação.

Dessa forma, acreditava-se poder reduzir as desigualdades escolares e, simultaneamente, defender o direito de permanência na escola. Entretanto, se, por um lado, a referida política pode garantir um maior acesso de alunos à escola e estender sua permanência; por outro, a problemática escolar das crianças parece estar deslocando-se para a saída do sistema de ensino. Em outras palavras, a não-retenção escolar dos alunos estaria caracterizando-se como uma mera aprovação automática, sem a devida garantia de que eles tenham adquirido o domínio das competências escolares mínimas esperadas pela sociedade para o seu atual momento de escolarização.
Os professores, os pais e mesmo os alunos têm questionado o fato de os alunos estarem passando de ano sem os conhecimentos e competências exigidos pela sociedade contemporânea. Assim, aqueles que anteriormente eram excluídos por não terem acesso ou possibilidades de permanência na escola, hoje seriam excluídos pelo não-domínio das competências escolares. Em função disso, tem-se aparentemente configurada uma certa resistência nos meios educacionais à estratégia política da nãoretenção escolar e suas implicações sociopedagógicas. Em recente avaliação da Proposta Escola Plural (UFMG, 2000), ficou constatado que uma das maiores dificuldades enfrentadas no processo de implantação dessa proposta foi a de convencer os professores da necessidade de eliminar as práticas e processos de reprovação escolar. Isso de deve à cultura da reprovação, que parece estar densamente incorporada no cotidiano escolar e no imaginário familiar como algo necessário e benéfico ao aluno em situação de fracasso escolar.

\section{- percurso investigativo e a escola municipal onde o estudo foi desenvolvido}

As questões norteadoras do estudo conduzem a uma abordagem metodológica qualitativa, centrada na produção do discurso dos sujeitos pesquisados em seu próprio ambiente de trabalho, ou seja, a escola. As entrevistas semi-estruturadas foram o principal instrumento na coleta de dados e possibilitaram a flexibilidade necessária para os atores discorrerem sobre as questões abordadas, informando e opinando sobre o tema proposto. Nas entrevistas, procurou-se privilegiar as percepções dos professores sobre a adoção do princípio da não-retenção escolar e de como este tem interferido em suas práticas pedagógicas e nas estratégias de sobrevivência escolar dos alunos de camadas populares. As entrevistas foram realizadas no período de outubro a novembro de 2000, na própria escola, em dia e horário pre- 
viamente marcados em função da disponibilidade de cada docente.

Além das entrevistas, foram ainda analisados alguns materiais obtidos na escola e na Administração Regional da Rede Municipal de Educação, tais como: o Projeto Político Pedagógico do $3^{\circ}$ Ciclo do turno da manhã, atividades trabalhadas pelos docentes com os alunos em sala de aula, dados levantados pelos professores da escola mediante a aplicação de questionários elaborados por eles mesmos junto à comunidade escolar, etc.

A análise do material discursivo obtido com a realização das entrevistas foi feita pelo método de análise de conteúdo. Mediante leitura e releituras do conteúdo das entrevistas, procurouse relacionar os dados levantados e definir, com base nas questões gerais propostas, categorias e subcategorias de análise. Os dados foram então classificados progressivamente, de acordo com as categorias estabelecidas. A descrição e a realização de inferências possíveis constituiu o passo seguinte, do qual adveio a interpretação dos dados, a fim de destacar alguns dos sentidos pertinentes aos discursos produzidos (Bardin, 2000).

A investigação foi realizada em uma escola da Rede Municipal de Educação de Belo Horizonte - RMBH -, cujo Projeto Político-pedagógico Escola Plural começou a ser implementado em 1995. Basicamente, essa escolha se justifica por ser a RMBH uma das pioneiras no Brasil a introduzir o princípio da não-retenção escolar na organização pedagógica das escolas, vindo a constituir-se em um referencial para os demais sistemas de ensino no país. No Programa Escola Plural, as mudanças implementadas na estruturação e organização do trabalho escolar têm o sentido de atender a dois princípios fundamentais: o direito à educação e a construção de uma escola includente. Desse modo, contemplam-se uma gestão mais democrática da educação; uma nova relação dos sujeitos com o conhecimento, ressignificando-o numa perspectiva globalizadora e transdisciplinar; uma nova concepção de avaliação, de caráter mais qualitativo e includente; a extinção da repetência e um novo ordenamento dos tempos escolares.
Mas, sem dúvida, a organização coletiva dos tempos e espaços escolares é o eixo central do trabalho proposto pela Escola Plural (Baptista, 1998). Nessa perspectiva, o Programa eliminou o regime seriado e instituiu três ciclos de formação básica, agrupando as crianças de acordo com sua faixa etária. Assim, a organização de Ciclos da Escola Plural abrange: $1^{\circ}$ Ciclo, alunos de 6 a 9 anos de idade; $2^{\circ}$ Ciclo, alunos de 9 a 12 anos de idade; $3^{\circ}$ Ciclo, alunos de 12 a 15 anos de idade. Essa concepção pedagógica coloca o aluno no centro da dinâmica do processo de ensino e aprendizagem e submete a organização do trabalho escolar e a proposta curricular à "formação e vivência sociocultural própria de cada idade ou ciclo de formação dos educandos" (Belo Horizonte, 1994, p. 16).

A escolha da escola municipal onde a pesquisa foi realizada se fez a partir dos seguintes critérios: 1. grande aceitabilidade do Programa da Escola Plural; 2. clientela predominantemente oriunda das camadas populares, ou seja, menos privilegiadas dos pontos de vista econômico e sociocultural; 3 . escola de nível fundamental, pois a incidência maior de reprovações ocorre nas séries iniciais. Para tanto, foram feitos contatos com a Secretaria Municipal de Educação de Belo Horizonte, levantando-se, na Coordenação de Política Pedagógica (CPP), uma relação de escolas que atendessem aos critérios estabelecidos. Optou-se, então, pela Escola Municipal Mário Quintana.'

A Mário Quintana funciona em três turnos diurnos (ou corridos) e em cada turno existem 22 turmas e cerca de 33 professores. A escola tem os três ciclos de formação em todos os turnos, ou seja, cada turno comporta um ano escolar de cada ciclo. $03^{\circ}$ Ciclo, por exemplo, é distribuído da seguinte forma: o $2^{\circ}$ ano no $1^{\circ}$ turno, o $3^{\circ}$ ano no $2^{\circ}$ turno e o $1^{\circ}$ ano no $3^{\circ}$ turno.

$\mathrm{Na}$ escola pesquisada, o procedimento inicial foi o de contatos preliminares com os professores a fim de selecionar os sujeitos a serem entrevistados. No caso, o $3^{\circ}$ Ciclo foi es-

1. Nome fictício dado à escola onde foi realizada a pesquisa. 
colhido para esta pesquisa por ser o ciclo final no nível fundamental de ensino, abarcando professores que atuam junto aos alunos com maior vivência no processo de escolarização, inclusive alunos que já passaram por situações de fracasso escolar expresso em forma de reprovação, repetência e evasão escolar. Assim, realizaram-se reuniões coletivas com dois grupos de professores do $3^{\circ}$ Ciclo que atuam nos $1^{\circ}$ e no $2^{\circ}$ turnos da escola, em parte do horário destinado às reuniões coletivas semanais. Cada reunião ocorreu em seu respectivo turno de trabalho e, nas discussões, procurou-se apreender as percepções mais gerais dos professores sobre o programa da Escola Plural e, especificamente, sobre a não-retenção escolar. A partir desse contato inicial, foram selecionados quatro professores para a realização das entrevistas. Os critérios para a seleção dos professores foram os seguintes: dois professores que se disseram favoráveis à não-retenção escolar e receptivos à nova proposta - Pedro Henrique e Silmara - e dois que se mostraram contrários num primeiro contato - Mariângela e Maria. ${ }^{2}$ Todos professores do $2^{\circ}$ ano do $3^{\circ}$ Ciclo, ano escolar correspondente à antiga $7^{\text {a }}$ série. Na verdade, do grupo de 21 professores contatados, somente dois deles se mostraram favoráveis à não-retenção escolar.

Além dos relatos desses quatro docentes, foram ainda considerados os depoimentos dos demais professores, da direção da Escola e dos coordenadores pedagógicos e de turno, com a intenção de enriquecer a análise e compreensão do posicionamento da escola no que tange ao Programa da Escola Plural e, em especial, à nãoretenção escolar. Mas a análise dos dados encontra-se mesmo centrada nas percepções dos quatros professores selecionados.

\section{Percepções e sentimentos em relação à implantação do Programa Escola Plural}

Os professores relatam como se sentiram despreparados e receosos com a implantação da Escola Plural. Afinal, não se tratava apenas de mais uma reformulação pontual em seu trabalho pedagógico, mas de uma mudança radical em toda a organização pedagógica e na cultura da escola. Os depoimentos permitem entrever um grau elevado de ansiedade e insegurança que, por sua vez, constitui um dos entraves à aceitação da proposta. Fica difícil aceitar o que não se compreende, quanto mais mudar uma prática pedagógica historicamente construída, tendo-se que assumir novas e diversas responsabilidades.

"Loucura”, "bagunça” e "confusão" são termos recorrentes usados pelos professores para designar os primeiros tempos da Escola Plural na escola pesquisada, sobretudo nos primeiros dois anos:

Foram cometidos muitos enganos! Sabe? Assim, tipo: 'Não preciso dar conteúdo mais!' Tipo: 'Não existe avaliação mais!' Então, assim, uma série de coisas que foram equivocadas e realmente, assim, a gente tá pagando o preço até hoje por uma série de coisas. Inclusive, com a matemática, né? Que só dava matemática... Muitas pessoas [que] só davam Matemática se encaixavam dentro de um projeto. Né? Então, eu percebo que houve um equívoco muito grande, apesar de muita gente acreditar na proposta da Escola Plural. (Mariângela)

Não tinha assim... Estrutura nenhuma! Era uma bagunça danada! Não tinha, assim, um critério de que se vai ensinar o aluno! Entendeu? Eu pegava aluno de... de... de $6^{\text {a }}$ e $7^{\text {a }}$ série, ele não sabia nem fazer... Nem os fatos fundamentais! Então... E foi aquela coisa de... de acelerar aluno que tava lá na $2^{\text {a }}$ série, né, antiga, acelerava lá pra $6^{\text {a }}$ série. Então foi uma loucura! Eu achei que foi uma coisa, assim, de louco mesmo! Os alunos que saíram, que pegou aquela fase de escola... Já tava caminhando e pegou Escola Plural... Esses saíram da escola sem condição nenhuma! (Silmara)

2. Os nomes fictícios dos entrevistados foram escolhidos por eles mesmos ao final das entrevistas realizadas. 
As dificuldades e equívocos cometidos quando da implantação da Escola Plural parecem expressar muitos desentendimentos acerca da proposta, como: não ser mais necessário avaliar e não mais trabalhar conhecimentos básicos escolares, a não ser quando relacionados a projetos cujos temas atendessem somente ao interesse dos alunos.

De acordo com esses professores, a Escola Plural veio legitimar algumas práticas que já vinham acontecendo na Rede Municipal, como o acompanhamento sistemático a alunos com maiores dificuldades no processo pedagógico; a reprovação que já não era dada em massa, mas mediante um consenso do grupo docente, após análise criteriosa de cada caso; as reuniões de sexta-feira, quando se buscava um trabalho pedagógico e administrativo em termos de decisões coletivas; as oficinas ocorridas na escola com um caráter de projeto. Mas eram mudanças que ocorriam de forma fragmentada, frágil, informal, dependendo sempre do espírito inovador de cada escola. Assim, os professores vinham inovando sua prática pedagógica, mas num ritmo próprio e de modo a atender às especificidades e particularidades de cada escola. Quando a SMED/BH determinou a implantação da Escola Plural de forma ampla, os professores expressaram seu descontentamento diante do que consideraram uma medida precipitada e pouco democrática.

Foram muitas as mudanças na organização pedagógica da Escola. Os tempos escolares foram reestruturados com a instituição dos ciclos de formação e da progressão continuada, buscando-se garantir princípios básicos como o respeito aos diferentes ritmos de aprendizagem e às diversidades culturais, o convívio dos alunos com seus pares de idade de formação e a garantia de continuidade do processo de formação dos alunos com o fim da retenção escolar. Instaurou-se o tempo coletivo, quando ocorrem as reuniões pedagógicas de planejamento, acompanhamento e avaliação. $\mathrm{Na}$ ruptura com os processos de ensino-aprendizagem tradicionais, baseados na concepção cumulativa e transmissiva de conteúdos escolares, novas propostas curriculares se apresentaram no espaço escolar e o trabalho pedagógico passou a ser organizado por meio de projetos. A prática avaliativa, até então pautada numa lógica seletiva e autoritária, foi reformulada para atender aos novos princípios. Na configuração de um processo mais formativo e inclusivo, a relação entre os sujeitos e o conhecimento foi profundamente modificada, com a busca de significados para os conteúdos escolares numa dimensão mais crítica e contextualizada (Belo Horizonte, 1994). Enfim, são pontos essenciais do Programa, percebidos e discutidos pelos professores no que tange ao modo particular de organização político-pedagógica estabelecida na escola, sobretudo no que diz respeito aos tempos escolares, à nova proposição curricular, à avaliação e à proposta de atendimento diferenciado dos alunos. No centro de tudo, o princípio da não-retenção-escolar é percebido como uma grande dificuldade na incorporação do novo modelo político-pedagógico implementado.

$\mathrm{Na}$ narrativa dos professores, percebe-se que essas mudanças mostram-se assimiladas muito mais no discurso do que, propriamente, na prática pedagógica. Assim, é que, embora o Programa defina uma ampliação considerável do tempo do professor nas escolas, com a contagem de 1,5 professores por turma para a definição de seu quadro docente - o que significa trabalhar com 50\% a mais de professores em relação ao número de turmas -, o professor continua a se defrontar com a questão de administrar mal o seu tempo e queixa-se de que, embora haja mais tempo para o desenvolvimento do seu trabalho, este se avolumou com a Escola Plural: o planejamento das aulas, a avaliação qualitativa e o cumprimento das demais tarefas, sem dúvida, requerem mais tempo e exigem mais desse professor.

Porque não vai dar tempo... Não adianta a gente falar que dois horários vai dar tempo [Uma professora: Não vai!], porque não vai dar tempo, né? Pelo amor de Deus! São muitos problemas!... 
(Diálogo de professores do $3^{\circ} \mathrm{Ciclo} / 1^{\circ}$ turno sobre tempo necessário para o Conselho de Classe) Tem hora que a gente esquece que tem que se cobrar mais, que tem que ter muito claro seus objetivos, senão você, realmente, fica ali, parado. Você não aproveita muito bem o tempo, né? (Pedro Henrique)

Alguns professores percebem a necessidade de racionalizar o tempo. Do contrário, a angústia pode muito bem causar uma certa imobilização pedagógica. Mas essa racionalização, na maioria das vezes, acaba por ocorrer de forma fragmentária, desordenada, dispersa. De acordo com Perrenoud (1997, p. 58), a dispersão é uma característica típica do professor na gestão do seu tempo de trabalho, que, "pressionado pelo tempo, prepara as tarefas mais urgentes, assegurando o mínimo de preparação para cada uma das atividades dos dias seguintes”.

A intensificação das exigências relativas ao trabalho docente induz os professores a economizar esforços, realizando somente o essencial para cumprir sua tarefa, o que acaba por estabelecer uma certa depreciação de sua experiência e competências adquiridas e construídas ao longo do tempo (Nóvoa, 1997). Assim, o professor tem consciência de que a planificação por ele realizada é mínima, mas que, em razão do tempo disponível, deve-se limitar ao essencial. E o faz não sem um certo sentimento de culpa por não conseguir se dedicar mais e melhor ao seu trabalho.

Sei que a gente poderia estar aproveitando muito melhor esse tempo também, né? Com 1,5 daria pra gente tá fazendo vários projetos mesmo de... de resgate desse conteúdo desses meninos que tão ficando pra trás, né? (Mariângela)

Das angústias sentidas pelos professores se destaca ainda a preocupação com os alunos que apresentam uma defasagem significativa na aquisição dos conhecimentos escolares. Para os professores, mesmo não sendo reprovados, esses alunos estão definitivamente ficando pra trás. Nesse sentido é que o tempo do aluno e, sobretudo, o tempo para o aluno, é também interrogado no discurso dos professores.

Eu acho que uma coisa que faltou, quando eles implantaram a Escola Plural, é aumentar o tempo do aluno na escola. Por que, que que adianta quatro horas com tanta coisa pra nós mesmos fazermos, né? Então, assim, é coisa demais pro aluno passar dentro de quatro horas só, né? (Professora do $3^{\circ}$ Ciclo $/ 2^{\circ}$ turno)

0 que eu acho ideal é que a gente consiga um atendimento extra-turno. Mas nós ainda não conseguimos viabilizar isso. [...] Tempo integral seria ideal, mas esbarra no pessoal, espaço... A coisa não é tão simples. (Diretora)

Mesmo que a Escola Plural tenha reestruturado o tempo, com a implantação dos ciclos e a ampliação do tempo de permanência do aluno de oito para nove anos no ensino fundamental, concedendo mais tempo ao aluno com a não-retenção escolar, os professores acreditam que o trabalho a ser feito demanda um tempo muito maior também numa outra esfera. A idéia, que parece ser consensual, é a de que a proposta inovadora da Escola Plural não cabe no tempo atualmente institucionalizado de quatro horas, quatro horas e meia por dia. Os docentes compreendem que, para ser de fato efetiva em seu propósito inclusivo, a Escola Plural deveria ser uma escola de tempo integral, ou, perante as dificuldades estruturais como espaço e pessoal, pelo menos ampliar o tempo do aluno e do professor na escola ao longo do dia.

Os docentes, ainda sem clareza da nova proposta curricular, continuam ancorados no antigo currículo formal, e a transposição didática realizada os mantém ainda mais distantes das novas proposições curriculares. Um exemplo disso consiste no trabalho com a chamada Metodologia de Projetos. 0 trabalho com projetos pedagógicos é considerado um grande avanço da Escola Plural, mas ainda é mal compreendido por muitos professores, que perma- 
necem atrelados ao livro didático e às aulas expositivas, denominando projeto a todo trabalho inter e multidisciplinar.

A seqüência do conteúdo continua a mesma. Não existe uma proposta curricular diferenciada. Ainda não foi feito um currículo que... Né? Pelo menos no $3^{\circ}$ Ciclo! Não existe uma proposta de currículo pro $3^{\circ}$ Ciclo. Fala-se de temas transversais, fala de... Mas na hora de você entrar pra sala de aula, você continua trabalhando com o conteúdo, quase que numa linha tradicional. (Professora do $3^{\circ}$ Ciclo $/ 1^{\circ}$ turno)

0 currículo ficou bem menor, né? 0 que a gente trabalha com o aluno é mais o trivial mesmo! Então, cê não dá coisas elaboradas, pensamento científico, não! Não, cê não trabalha isso com o aluno não! Trabalha com o trivial mesmo, o mínimo necessário pra ele sair da escola. (Silmara)

Ainda no que tange à reformulação do currículo, para os professores, mesmo havendo o cuidado de se abordarem temas que atendam à formação sociocultural dos alunos, persiste a convicção de que não se deve descuidar dos conteúdos escolares. Além disso, acreditam que a atual organização pedagógica em ciclos, sem que haja retenção, esteja permitindo somente o desenvolvimento de um currículo mínimo (e mínimo não no sentido de essencial). Como o aluno é promovido, independentemente dos conhecimentos e das competências escolares adquiridos, gradativamente eles ascendem em seu percurso de escolarização cada vez com mais dificuldade, por não terem o domínio desses conhecimentos e competências. Assim, na percepção do professor, não resta outra alternativa senão trabalhar apenas o que é viável dentro das condições de aprendizagem dos alunos. Por exemplo, com alunos do $2^{\circ}$ ano do $3^{\circ}$ Ciclo que ainda não adquiriram a competência para uma leitura fluida e compreensiva, os professores tendem a desenvolver um curriculo condizente com uma turma de $1^{\circ}$ Ciclo que se encontra no início de seu percurso de escolarização. Os professores avaliam que esse programa curricular estabelece uma expressiva distância em termos de conhecimentos entre os alunos da Mário Quintana e alunos de outras escolas, cujo ensino se realiza em bases consideradas tradicionais.

No que se refere ao processo de avaliação, o discurso sobre uma avaliação diagnóstica, qualitativa, formativa parece ter sido bem assimilado. Os professores afirmam que já mudaram muito sua forma de avaliar. Mas, se não mudaram mais, é porque estão em processo de mudança.

Mudou porque eu consigo fazer hoje uma ava-
liação mais contínua, mais processual... E antes
não: minha avaliação era final de bimestre, ti-
nha que ter prova... Ai, se eu não desse uma
prova! Hoje em dia, eu continuo dando prova,
é um instrumento a mais de avaliação! (Maria)

Mas, na prática, as dificuldades são visíveis. Os professores se perguntam: $O$ que avaliar? Como avaliar? Embora se diga muitas vezes o que o professor deve ensinar, os programas oficiais se abstêm de definir com clareza o que os alunos devem aprender, portanto, o que se deve avaliar (Perrenoud, 1999). Mas a dificuldade maior para o professor assumir e incorporar ao seu habitus ${ }^{3}$ profissional uma avaliação mais formativa e democrática parece dever-se ao aspecto decisório da avaliação, que é sócio-historicamente construído. Ou seja, avaliar sempre implicou fundamentar uma decisão: o aluno deve ou não prosseguir com o curso? Ele está apto a receber um certificado referente às suas aquisições escolares (Perrenoud, 1999)? Com o advento da Escola Plural, a ênfase avaliativa, até então centrada nos resultados da

3. Segundo Bourdieu (1983, p. 61), o habitus são "sistemas de disposições duráveis, estruturas estruturadas predispostas a funcionar como estruturas estruturantes, isto é, como princípio gerador e estruturador das práticas e das representações que podem ser objetivamente 'reguladas' e 'regulares' sem ser o produto da obediência a regras, objetivamente adaptadas a seu fim sem supor a intenção consciente dos fins e o domínio expresso das operações necessárias para atingi-los e coletivamente orquestradas, sem ser o produto da ação organizadora de um regente". 
aprendizagem, expressos nas notas e nos boletins escolares, é transposta para o processo educativo que se pretende formativo e igualitário. Nos termos propostos, reprovar não mais resulta de uma decisão do professor ou do grupo docente. Essa decisão já está tomada, independentemente do nível das aquisições escolares do aluno e de quaisquer outros fatores (como idade e progressos recentes do aluno, projetos, pressões da família, atendimento previsível na etapa seguinte, etc.). 0 professor não mais dispõe do poder de decisão resultante do seu laborioso trabalho de avaliação: ele não pode mais reprovar.

E a gente escuta muito a fala do aluno, assim: 'Ah, eu vou passar mesmo. Eu já passei mesmo', né? Eles ainda continuam tendo aquela idéia de que... Passar ou não passar, né, pra eles ainda fica... É... forte essa questão de passar ou não passar. Mas eles sabem que aqui não... não tem essa... essa questão de passar de ano... Não se envolvem com as atividades... por causa desse motivo, né? Eles sabem que não... não existe a retenção. (Professora do $3^{\circ}$ Ciclo $/ 1^{\circ}$ turno)

Agora, a escola é plural? É. Permite inclusive que... que alunos que não têm a menor capacidade, né, avancem ali na Escola Plural... Que ela prevê, ela dá essa abertura... Não é? Então, a Escola Plural, realmente... Ela dá... dá muita liberdade, dá muito direito... Mas... não... não tem como, não tem armas pra cobrar os deveres do aluno. Porque até o Conselho Tutelar, a Justiça, não sei o que, garante a ele esse direito! (Professor do $3^{\circ}$ Ciclo $/ 2^{\circ}$ turno)

Com relação ao registro da avaliação, a SMED/BH propôs, desde o início, a elaboração de uma ficha qualitativa que expresse o processo escolar do aluno da forma mais ampla possivel, englobando aspectos cognitivos, afetivos, de socialização, etc. (Belo Horizonte, 1994). As escolas têm autonomia para criar suas próprias fichas de avaliação. Na escola pesquisada, a ficha avaliativa utiliza conceitos (MB - muito bom, B - bom, R - regular, AD
- apresenta dificuldades) na avaliação das disciplinas curriculares e também de aspectos como cumprimento de tarefas, participação nas aulas, freqüência, pontualidade, relacionamento com professores e colegas, etc. Essa avaliação é registrada em três momentos, em três etapas do processo. No verso da folha, há ainda um espaço para observações acerca do aluno. Como se constatou, em alguns casos, esse espaço não é preenchido ou o é de forma pouco particularizada. Há a colagem de um mesmo enunciado para certos alunos dizendo da sua falta de compromisso com as questões escolares e em quais conteúdos apresentam defasagem. Não foi averiguado se há também um discurso já pronto, padronizado, para os alunos compromissados ou se, nesse caso, os professores considerem a medida desnecessária. Sem dúvida, tal estratégia parece ser decorrente da falta de tempo dos professores para arcar com uma avaliação mais qualitativa e de caráter descritivo. Mas o fato é que, sem a avaliação seletiva e a conseqüente retenção escolar, insatisfeitos com a perda de seu principal instrumento de distribuição do conhecimento escolar, de poder, de diferenciação e controle sobre o aluno, os professores tendem a criticar e deturpar o propósito oficial da ficha avaliativa.

Por exemplo, se fosse uma escola boa, olhava a ficha dele. Não tem condições de freqüentar essa escola e não pensava duas vezes. Entendeu? Eu acho que... Já que não pode ter prova, não pode ter reprovação... Ele vai... É igual ficha suja... [Uma professora brinca e ri: 'Fichado!' Outros professores também riem.] Todas as ocorrências que ele cometeu na escola, tá anotado lá, ó! Sabe, ter assim uma ficha corrida toda dele! E, no final, quando ele sair da escola, ele sabe: a ficha que a gente vai mandar pra qualquer pessoa que pedir é essa aqui! Essa foi sua vida nessa escola...

A proposta do professorado é a de instituir um outro mecanismo de controle, de caráter nitidamente punitivo e que venha a dar suporte 
suficiente ao professor para resgatar seu poder disciplinador: o uso da ficha avaliativa. Nela, tudo seria registrado, e a ficha serviria de certificado de competência ou incompetência do aluno perante a sociedade. Dessa forma, a ficha se constituiria num mecanismo de advertência e de possível punição para o aluno, devolvendo, em parte, ao professor sua competência e seu poder decisório sobre o destino escolar dos alunos.

De todo modo, a nova forma de avaliar é considerada positiva. Os professores reconhecem, em sua maioria, que a avaliação formativa tende a favorecer a aprendizagem do aluno. Entretanto, têm também consciência de que essa concepção de avaliação requer um trabalho singular com os alunos, na medida em que os ritmos de aprendizagem são diferentes. Todavia, o pretendido atendimento diferenciado na escola tem-se limitado à existência das turmas-projeto, formadas por alunos que, na avaliação de seus professores, não têm o domínio de competências e conhecimentos considerados básicos para o ano escolar no qual se encontram. Os professores apresentam percepções ambivalentes com relação às turmas-projeto. Se, por um lado, entendem que, para os alunos que apresentam maiores dificuldades de aprendizagem, as turmas-projeto são importantes por se constituírem no único recurso pedagógico disponível na escola, em que os alunos têm a chance de serem atendidos de forma diferenciada em sua significativa defasagem de aprendizagem, por outro, se angustiam com os poucos resultados obtidos. Essa forma de atendimento diferenciado é, na verdade, percebida pelos professores como uma medida paliativa e insuficiente. Segundo eles, faz-se necessária a construção de alternativas pedagógicas que permitam um melhor acompanhamento dos muitos alunos que demandam um atendimento específico, algumas vezes individualizado. Para tanto, dizem, são necessárias condições de materialidade, como espaços físicos adequados na escola e mais professores disponíveis e qualificados para o trabalho.

\section{A perda da autoridade pedagógica e as ambigüidades em relação à prática docente e à vida escolar}

No relato dos professores sobre sua prática pedagógica, eles comentam, principalmente, as dificuldades sentidas no exercício de sua profissão. Contam que sofrem pressão de cima, daqueles que ficam apontando seus erros, sem entender que chegar à prática e fazer não é fácil; que são sempre eles os culpados por tudo; que estão desanimados com o sistema de ensino; que têm ficado mais cansados; que, muitas vezes, vêm apenas empurrando com a barriga, mas que isso os faz sofrer; que se angustiam porque não vêem o resultado de seu trabalho; que sentem falta de ânimo, falta de entusiasmo e até desespero em face de seu trabalho pedagógico. As reuniões pedagógicas, que, a princípio, são momentos de planejamento, organização e discussão do trabalho, têmse convertido, de acordo com os próprios professores, num verdadeiro muro das lamentações, em que todos expõem suas angústias e só lamentam e lamentam acerca do trabalho.

A eliminação da reprovação - concebida como um mecanismo regulador das aprendizagens e da disciplina dos alunos - tem, portanto, engendrado situações de insegurança e de conflito entre os professores. Para eles, a adoção da não-retenção escolar tem propiciado o que denominam de nós no trabalho desenvolvido na escola e contribuido para uma mudança no valor dado à escola, ao estudo e à escolarização, sobretudo pelos alunos e por suas famílias. Dentre esses nós, a queixa sobre a falta de limites dos alunos está sempre presente na fala dos professores que entendem que a postura de completo descaso com as normas estabelecidas está associada à ausência de uma cobrança sistemática, ao disciplinamento e ao controle exercidos por meio de provas, notas, da assinatura dos pais nos boletins e retenção, a que os alunos já estariam acostumados. 
Eu acho que tiraram todas nossas armas. As armas que a gente tinha era reprovação, era nota, né? Tiraram todas... (Professora do $3^{\circ}$ Ciclo $/ 1^{\circ}$ turno numa reunião de professores)

Agora, completamente desarmados, os professores sentem-se amarrados: não sabem o que fazer após a abolição dos velhos mecanismos conhecidos de controle e de punição. Parece que, impossibilitados de exercer seu poder mediante os mecanismos tradicionais, ainda não conseguem instituir uma nova autoridade com base em outro mecanismo regulador dos comportamentos e das aprendizagens. Eles se percebem como sujeitos desautorizados no exercício de sua função, que, para ser efetiva, deve ter sua autoridade pedagógica legitimada institucionalmente e reconhecida pelos alunos.

No dizer dos professores, o desinteresse do aluno é considerado também um dos grandes entraves da Escola Plural. ${ }^{4}$ Cientes de que irão passar de ano independentemente de seu investimento, os alunos não se interessam, não se envolvem com as atividades.

Na verdade, nós estamos aqui, na nossa escola, com um número muito grande de alunos, que, com o evento Escola Plural, eles simplesmente cruzaram os braços. Porque eles pensam o seguinte: que com a Escola Plural nada vai impedi-los de seguir à frente. (Pedro Henrique)

Da mesma forma que os professores não conseguiram ainda modificar sua relação com o saber, permanecendo mais numa postura de transmissão dos conhecimentos do que respaldados por uma lógica da aprendizagem e da construção dos conhecimentos, nota-se, pela narrativa docente, que os alunos também não alteraram a relação utilitarista mantida com o saber, em que a valorização dos conhecimentos e das competências torna-se relativamente proporcional aos ganhos tangíveis. A maioria dos alunos, vivendo anos e anos numa lógica utilitarista respaldada pelo próprio sistema escolar, estudava, simplesmente, para obter uma boa nota, para passar de ano, para agradar aos pais, para ganhar aquele presente, etc. Assim, seria motivo muito maior de estarrecimento se os alunos, sem que os professores houvessem desenvolvido estratégias e intervenções adequadas, reconstruíssem sua relação com o saber pautada "pelo sentido que ele dá à realidade, pelo enriquecimento pessoal que propicia, pela movimentação ou pela satisfação da mente que favorece" (Perrenoud, 1999, p. 69). Cabe ainda considerar que, na relação da escola com a sociedade, as expectativas de ascensão social são construídas em face de uma avaliação, não necessariamente consciente, que professores, alunos e pais realizam das possibilidades de sucesso escolar. Os investimentos, tanto da parte do aluno e da família como da escola, costumam ser proporcionais às chances calculadas de progresso escolar que possam ser futuramente convertidas em ganhos econômicos e sociais. Se as estimativas de sucesso mostramse pouco animadoras, a tendência dos alunos parece ser a de uma acomodação à situação de fracasso vivenciada. 0 que algumas vezes costuma ser interpretado como desânimo diante das questões escolares pode estar, na verdade, traduzindo um certo realismo das classes menos favorecidas quanto a um sistema educacional escolar reconhecidamente seletivo e excludente (Bourdieu, 1998).

Em tom de denúncia, os professores dizem também que mesmo os alunos infreqüentes durante quase todo o ano letivo são promovidos e seguem acompanhando sua turma. Ainda mais grave é a situação dos alunos que estão chegando ao $3^{\circ}$ Ciclo mal sabendo ler e escrever, o que estaria emperrando o trabalho pedagógico desenvolvido em todas as disciplinas. Essa forma de seletividade e de exclusão no interior da própria escola em nenhum momento é atribuída como sendo também de responsabi-

4. A questão das percepções dos alunos da escola pesquisada e de suas famílias a respeito do impacto da não-retenção na vida escolar é contemplada no artigo "A 'escola dos que passam sem saber': a prática da nãoretenção escolar na narrativa de alunos e familiares" que foi publicado na Revista Brasileira de Educação n. 22 em jan/fev/mar/abr. 2003. 
lidade da instituição e do corpo docente. Pelo contrário, os professores tendem a retirar de si a responsabilidade pelo processo de ensinoaprendizagem. 0 problema é geralmente creditado ao próprio aluno que se recusa a estudar como deveria.

Se você dá a opção ao aluno dele estudar se quiser... 0 adolescente... Por exemplo, eu falo que o adolescente não quer ter trabalho. 0 adolescente não quer estudar! Dificilmente vai achar um adolescente que quer... queira realmente estudar, que ele tenha consciência do que aquilo vai trazer pra ele futuramente! Eles não têm essa cabeça! Eles vivem o aqui e o agora! Os nossos alunos daqui... Eles não querem estudar! Cê tira um ou outro que realmente vem na escola porque pensa em alguma coisa mais futura! Os nossos alunos são imediatistas: é tudo hoje! Não quer saber o que vai acontecer amanhã! Então, isso dificulta a aprendizagem! E com esse negócio de não ter avaliação com nota, não ter retenção... Aí eles se sentem mais à vontade ainda! De chegar aqui na sala de aula e falar assim: 'Hoje eu não vou fazer nada!' E não há quem obrigue eles a fazerem! Por mais que você tente diversificar, mudar sua aula, fazer coisas diferentes... Fazer coisa diferente pra eles é ir pra quadra jogar bola... É só isso que agrada! (Silmara)

Ao desabafo dessa professora se contrapõe fortemente uma advertência de Perrenoud (1999, p. 97): "Ninguém pode crer que basta propor projetos ou apelar para a criatividade dos aprendizes para que todos se mobilizem, longa e seriamente, e assumam sua própria aprendizagem”. Os professores insistem recorrentemente em culpar os alunos por não estudarem sem, todavia, se envolverem no processo de ensino-aprendizagem e se interrogarem sobre qual e como têm desempenhado o papel que lhes cabe de reconstruir o contrato didático ${ }^{5} \mathrm{em}$ termos de formação de novos hábitos pelos alunos. A única resposta perceptivel dos professo- res parece ser a pura e simples lamentação. A ação tá paralisada! A gente tá só na... na
lamentação, né? (Professora do $3^{\circ}$ Ciclo/ $1^{\circ}$
turno)

De repente, cê chega numa reunião... cria um muro de lamentação. 0 pessoal fica assim: 'Meu Deus! Que desespero! Eu não consigo dar aula! Que ninguém aprende nada! Que ninguém faz nada! Os meninos não querem nada!' [...] E eu me angustio quando eu vejo, quer dizer, percebe isso, vê onde tá o problema e a gente, enquanto isso...

São compreensiveis as lamentações dos professores em relação à vida escolar. 0 que parece problemático é a insistência e a permanência com que se lamentam, indício de uma identidade profissional ainda inconsistente, na medida em que se apresenta insegura e limitada no exercício de sua competência (Costa, 1995). Dessa forma, os professores não se dispõem a desconstruir esse muro de lamentações e intervir no processo pedagógico de forma mais efetiva e diferente do que até então vinham realizando. Sem isso, tornam-se difíceis a análise e o avanço nas questões que se apresentam como problemáticas em seu exercício profissional.

Ante as dificuldades relatadas, os professores dizem que, em alguns casos, ainda podem contar com a ajuda da família. Mas isso não é o usual. Mesmo porque muitos pais sentem a mesma dificuldade dos professores, já que a ameaça da bomba não existe mais. Assim, um outro nó apontado pelos professores refere-se à omissão da família no processo educacional escolar.

É, eu acho que com esse evento aí da Escola Plural, né, a não-retenção influenciou negativamente. Eu acho que o pai também se... A família se tranqüilizou. Pela família não ter mais essa... 0 assombro da reprovação, da 'bomba'

5. "0 contrato didático é o acordo implícito ou explícito que se estabelece entre o professor e seus alunos a propósito do saber, de sua apropriação e de sua avaliação" (Perrenoud, 1999, p. 118). 
(entre aspas), eu acho que eles também se acomodaram. Houve um acomodamento, houve uma tranqüilidade tão grande... E aí, isso é negativo. É difícil conseguir que a gente faça que o aluno, ele tem que caminhar. Porque o aluno... Ele é um todo, né? Ele é um todo que precisa da ação da escola, precisa da ação da família. Eu acho que a ação da família tem sido omissa. (Pedro Henrique)

De acordo com os professores, o acompanhamento da família que já não era muito bom, piorou, pois os pais não se empenham tanto quanto se empenhavam antes, quando havia reprovação na escola. Eles entendem que o papel da família seria dialogar com esse aluno sobre a importância do estudo para o futuro, participar das reuniões de pais na escola, averiguar os cadernos e cobrar mesmo do filho uma real postura de aluno, ou seja, o que corresponde, no imaginário dos professores, à postura do bom aluno: estudioso, interessado, participativo, respeitoso, etc. Assim, os professores criticam e lamentam a omissão das famílias, mas também não intervêm no sentido de buscar sua cooperação seja em que nível for.

Os docentes relatam ainda existir uma discordância da comunidade escolar em relação à Escola Plural, especialmente no que diz respeito à não-retenção escolar. Segundo os professores, alunos e pais parecem desejar a volta da bomba, da reprovação, compreendida como um mecanismo de controle fundamental e insubstituível, sem o qual alunos se tornam irresponsáveis por saberem que passam de qualquer jeito. Reportando-nos, porém, aos estudos acerca da reprovação, vemos que os argumentos em sua defesa não se sustentam. A suposição de um senso comum sobre o valor moral da reprovação, que ensina ao aluno a importância do empenho e disciplina, parte do pressuposto errôneo de que o fracasso escolar é culpa do aluno, quando, na verdade, existem vários fatores imbricados e configurados de modo complexo e singular na definição de uma trajetória escolar (Silva; Davis, 1993). Aqueles que consideram a repetência uma nova chance para aprender desconhecem ser a prática pedagógica da reprovação um grave equívoco que, além de não garantir a aprendizagem, provoca no aluno um sentimento de inferioridade e de desprestígio (Leite, 1999; Oliveira, 1997). Quanto à idéia de que a reprovação na escola prepara a criança para a vida social, pois ensina a lidar com a competição e a seletividade, desconsiderase que o sucesso social se relaciona à capacidade e ao esforço individuais, mas também a vários fatores de ordem histórica, econômica, política e social e, até, ao acaso (Leite, 1999).

Um outro problema percebido pelos professores é a constatação de uma lacuna entre teoria e prática. Consideram boa a proposta da Escola Plural, mas percebem que, na prática, há muitas falhas. Entre essas falhas, apontam a falta de uma infra-estrutura adequada. Os professores reclamam de a SMED/BH não ter propiciado as condições materiais necessárias à Escola Plural e prometidas quando de sua implantação.

Outra grande dificuldade diz respeito à atuação dos professores do $3^{\circ}$ Ciclo. De acordo com os docentes, o trabalho desenvolvido no $3^{\circ}$ Ciclo tem algumas peculiaridades que dificultam sua concretização nos moldes propostos pela Escola Plural. Entre outros, destacam o fato de lidar com a adolescência ou mesmo a composição do quadro docente que atua no $3^{\circ}$ Ciclo ser de professores $P 2$, tradicionalmente acostumados a atuar individualmente em sua área específica. Os professores do $3^{\circ}$ Ciclo sentem dificuldade em perceber o desenvolvimento dos conteúdos curriculares por meio dos projetos e, com base nisso, se abstêm, muitas vezes, de participar dos projetos propostos. Eles tendem também a conceber os projetos como necessariamente envolvendo conteúdos de todas as disciplinas, quando, na perspectiva da Escola Plural, o projeto não tem intrinsecamente esse caráter. Esses professores parecem se opor ao desenvolvimento de projetos, como se os mesmos invadissem sua área específica de formação e os obrigassem a se imiscuírem em outras especialidades. De fato, como esclarece 
Amaral (2000, p. 73) referindo-se ao $3^{\circ}$ Ciclo,

nesse nível, começa a delinear-se, com mais clareza, a necessidade de clarificação e estruturação dos campos de saber. A própria formação dos professores (licenciaturas em disciplinas específicas) torna-os muito ciosos dos estatutos disciplinares, e isto atua na direção contrária à abordagem interdisciplinar, mais globalizadora. 0 trabalho coletivo, envolvendo professores de diferentes áreas, ainda é um grande desafio.

Assim, a proposta da interdisciplinaridade, por exemplo, é algumas vezes rejeitada em função da formação mais especializada do profissional que atua no $3^{\circ}$ Ciclo e que não os preparou para uma perspectiva pedagógica de construção do conhecimento.

É possível perceber que todos esses nós - aprendizagem defasada, indisciplina, desinteresse e infreqüência do aluno, discordância da comunidade escolar, falta de infra-estrutura, peculiaridades do trabalho desenvolvido no $3^{\circ}$ Ciclo, formação especializada do corpo docente -, quando não constituídos a partir da não-retenção escolar, encontram-se a ela entrelaçados.

Agora, [a escola] é um cilindro que passa manteiga e que passa todo mundo. (Professora do $3^{\circ}$ Ciclo/ $/ 1^{\circ}$ turno)

A fala dessa professora ilustra bem a imagem que muitos dos docentes têm da Escola Plural com a não-retenção. Nessa visão, a Escola Plural tem facilitado a promoção do aluno de uma forma equivocada. E o equívoco está justamente no fato de, segundo os professores, não existir mais empecilho nenhum na escolarização do aluno no ensino fundamental. Ele certamente irá concluir essa primeira etapa sem nenhuma dificuldade para superar, o que leva muitos a acreditarem que, na Escola Plural, tudo é demasiadamente fácil. E, no raciocínio dos professores, a realidade - entendida como a lógica da sociedade em que a escola está inserida - não é bem assim. As demais escolas e mesmo o mercado de trabalho atuam numa outra lógica, ainda seletiva e excludente. Portanto, essa extrema facilidade há de se converter, na saída da Escola Plural, num grande obstáculo para a vida escolar e profissional desse aluno.

Os professores afirmam, de todo modo, que mudanças têm ocorrido em sua prática pedagógica.

Mudou muito a minha prática! Eu acho que pra melhor! Porque todos os dias eu dô um jeitinho de chegar, pegar o jornal, dá uma olhada, vê se tem alguma coisa dentro do Projeto que eu tô trabalhando pra tá passando pra eles, tá crescendo... Quer dizer, essa é uma mudança positiva. [Outras mudanças que você percebe na sua prática...?] Com relação... é... com relação a avaliação, a... ao conhecimento... organização e também a questão de... de... relacionamento com aluno, acho que melhorou. Que até então a gente era mesmo... Eu era mesmo mais autoritária! Eu que decidia... Hoje eu já consigo decidir junto com eles... (...) Foram mudanças, assim, interiores, que foram difíceis pra mim! Né, por eu ter vivenciado tanto tempo... E vivencio ainda a Escola Tradicional em muita coisa! (Maria)

Eu acho que se hoje falasse assim: 'Não, não vai haver Escola Plural mais!', muitas coisas que nós avançamos, a gente não voltaria atrás, né? Apesar de alguns dizerem que não gostam da Escola Plural... (Mariângela)

Os professores contam que, antes da implantação do Programa da Escola Plural, eram muito tradicionais, as aulas eram invariavelmente do tipo quadro e giz. 0 fundamental, nessa ótica, era dar conteúdo, sempre seguindo e trabalhando o livro didático, do início ao fim do ano. As avaliações aconteciam aos finais de cada bimestre, individuais, com o aluno tendo que provar seu aprendizado. Mas, hoje, sua prática pedagógica teria mudado muito em virtude da nova proposta: existe o entendimen- 
to de que o aluno é o centro do processo pedagógico, devendo ser estimulado em seu potencial, e os conteúdos trabalhados devem ser sempre no sentido de propiciar a esse aluno as condições para viver neste mundo de forma competente, como cidadão crítico. Nessa perspectiva, os docentes dizem que procuram dar aulas diferentes, mais atraentes, e a avaliação é mais contínua, processual. Para isso, alguns relatam que procuram estudar e se manterem informados. Admitem que é mais difícil, dá mais trabalho, mas que essa mudança em sua prática pedagógica é positiva. Assim, é possivel perceber um novo professor se delineando na escola, sem dúvida, um professor mais plural, que parece arcar com a angústia diante da nova concepção de ser professor e do processo de reconstrução da identidade profissional. Dessa forma, embora a insatisfação com o próprio trabalho se mantenha atrelada às conquistas, os professores acreditam que é possível e que se deve mudar.

Esses professores reconhecem o mérito da Escola Plural em seu propósito includente. Percebem que os alunos que evadiam, muito em razão da repetência, hoje permanecem na escola, porque não há mais retenção escolar e raciocinam que, se hoje existem tantos alunos com sérias dificuldades ante o processo de ensino-aprendizagem, é porque se trata de alunos que anteriormente eram excluídos da escola. Assim, é um equívoco, na avaliação de alguns professores, dizer que a Escola Plural e a não-retenção são as responsáveis pelos problemas de aprendizagem hoje existentes em proporção muito mais elevada na escola. Entretanto, são unânimes em julgar que as chances de sucesso do aluno se restringem à sua maior permanência na escola. Por isso, alguns professores dizem tratar-se de um sucesso entre aspas. Tanto os professores que se dizem contrários à não-retenção como os que afirmam sua concordância têm percepções muito próximas, senão as mesmas, sobre a questão. Quando os professores reclamam da não-retenção é, sobretudo, porque, embora ela tenha permitido ao aluno permanecer na escola, eles entendem que essa é uma inclusão ainda parcial.

A questão da Escola Plural é uma proposta de inclusão! Nós estamos incluindo esse aluno na Escola Plural para excluí-lo na sociedade. Porque, uma vez que ele sai daqui sem a preparação adequada, nós estamos contribuindo para alimentar nele a ilusão de que ele está preparado, quando sabemos que ele não está. Ele não vai ter condições de competir. (Professor do $3^{\circ}$ Ciclo/2 $2^{\circ}$ turno)

Para os professores, é evidente que a exclusão continua a existir mesmo após a eliminação formal da retenção escolar, e que o fracasso escolar é ainda um mal presente na vida de muitas crianças e adolescentes.

\section{Considerações finais: continuidades e avanços na atuação dos professores}

É de amplo conhecimento que as reformas de ensino e projetos político-pedagógicos inovadores passam por processos de decodificação e por modificações ao longo de sua implantação nas instituições escolares. As escolas se configuram como espaços socioculturais com funções que ultrapassam os meros ajustes ou adaptações emanados dos órgãos de gestão do sistema de ensino. 0 cotidiano escolar é algo vivo e em intenso processo de transformação, com ritmos, vivências, interações, redes informais, de sentido e de informações, e crenças pedagógicas construídas de forma lenta e em constante interação entre seus atores com a cultura mais ampla. São essas vivências em ação nas escolas que engendram um ethos sociocultural e pedagógico e marcam diferenças e semelhanças entre elas, tornando mais lentos ou mais rápidos a incorporação de inovações e os processos de transformação que, em princípio, parecem acordados e desejados por todos. Segundo Certeau (1993), toda mudança requer das instituições e dos sujeitos 
um modo de apropriação, uma adoção e uma transformação pessoais, uma espécie de culturação, além de um intercâmbio instaurado em um grupo social. Qualquer inovação pedagógica toca assim em aspectos fundamentais da cultura escolar e insinua um novo comportamento cultural.

Os relatos acima descritos do processo de incorporação da Escola Plural e do princípio da não-retenção escolar revelam que os professores na escola estudada se situam em momentos distintos e distintivos perante as mudanças propostas na cultura escolar. É possível perceber a presença de um movimento intenso e conflituoso de reformulação de identidade social e profissional desses professores, ao se colocarem entre o antes da Escola Plural e as experiências agora vividas no espaço escolar. De um lado, parecem empenhados em preservar certas crenças e valores que têm historicamente fundamentado suas concepções e ações relativas ao processo de ensinoaprendizagem, como se essa perda implicasse o desmoronamento de sua própria identidade de professor. De outro lado, sentem, igualmente, que necessitam rever seus referenciais epistemológicos, teóricos e práticos e reconstruir sua identidade docente no sentido de se situarem mais profissionalmente perante as transformações sociais e pedagógicas colocadas para a escola e na escola.

Na percepção desses docentes há uma evidente contradição entre a proposta da Escola
Plural e a estrutura social que permanece competitiva, seletiva e excludente. Nas escolas de ensino médio, ainda prevalecem notas, provas e reprovações. Há os vestibulares e os concursos. Há uma competição acirrada por empregos no mercado de trabalho, com exigências cada vez maiores quanto à formação escolar. Os professores percebem, pois, que a não-retenção escolar seria, na verdade, um passo decisivo para o sucesso escolar, mas não o passo definitivo. A situação é complexa e, por isso, eles se opõem, sim, à forma como a não-retenção escolar foi implementada na Escola Plural, o que, para eles, tem implicado efeitos perversos: os alunos continuam a ser excluídos quando terminam o ensino fundamental, haja vista não disporem de competências e saberes mínimos necessários a uma atuação efetiva no mundo no qual transitam.

Os professores concordam entre si que se torna imprescindivel um ensino de qualidade que assegure a promoção com aprendizagem efetiva. Nessa perspectiva, o fracasso escolar e a exclusão persistem no âmbito da Escola Plural. E é isso, na verdade, que os professores não admitem - embora pareça que encontrem dificuldades para alterar essa realidade -; é isso que eles acreditam que precisa ser revisto com urgência. Segundo os professores, a Escola Plural é um sonho possível, sim. Mas acreditam que se no meio do caminho tem uma pedra, o caminho pode ser revisto e novos caminhos podem ser trilhados. 


\section{Referências bibliográficas}

AMARAL, A. L. Os projetos de trabalho na ótica da Escola Plural. In: DALBEN, A. I. L. de F. (Org.). Singular ou plural? Eis a escola em questão! Belo Horizonte: GAME/Fae/UFMG, 2000, p. 67-75.

BAPTISTA, M. C. Escola Plural: direito a ter direitos. Secretaria Municipal de Educação. Belo Horizonte: SMED - Secretaria Municipal de Educação. Disponível em: <http://www.belohorizonte.mg.gov.br/smed/escoplur/escoplu00.htm> Acesso em: 18 abr 1998.

BARDIN, L. Análise de conteúdo. Lisboa: Edições 70, 2000. 230 p.

BELO HORIZONTE Secretaria Municipal de Educação. Escola Plural: proposta político-pedagógica da Rede Municipal de Educação. Belo Horizonte: SMED, 1994.

BOURDIEU, P. Esboço de uma teoria da prática. In: ORTIZ, R. (Org.). Pierre Bourdieu: sociologia. São Paulo: Ática, 1983, p. $46-81$.

A escola conservadora: as desigualdades frente à escola e à cultura. In: NOGUEIRA, M. A.; CATANI, A. (Orgs.). Escritos de educação: Pierre Bourdieu. Petrópolis: Vozes, 1998, p. 39-64.

CERTEAU, M. de. A cultura no plural. Campinas: Papirus, 1993. 253 p.

COSTA, M. C. V. Trabalho docente e profissionalismo. Porto Alegre: Sulina, 1995. 280 p.

CURY, C. R. J.; HORTA, J. S. B.; FÁVERO, 0. A relação educação-sociedade-estado pela mediação jurídico-constitucional. In: FÁVERO, 0. (Org.) A educação nas constituintes brasileiras: 1823-1988. Campinas: Autores Associados, 1996, p. 5-30.

CURY, C. R. J. A educação como desafio na ordem jurídica. In: LOPES, E. T.; FARIA FILHO, L. M.; VEIGA, C. G. (Orgs.) 500 anos de educação no Brasil. Belo Horizonte: Autêntica, 2000, p. 567-584.

FORQUIN, J. C. (Org.). Sociologia da educação: dez anos de pesquisa. Petrópolis: Vozes, 1995. 350 p.

GATTI, B. A. Enfrentando o desafio da escola: princípios e diretrizes para a ação. Cadernos de Pesquisa, São Paulo, n. 85, p. 510, maio 1993.

HORTA, J. S. B. Direito à educação e obrigatoriedade escolar. Cadernos de Pesquisa, São Paulo, n. 104, p. 5-34, jul. 1998.

LEITE, D. M. Promoção automática e adequação do currículo ao desenvolvimento do aluno. Estudos em Avaliação Educacional, São Paulo, n. 19, p. 5-24, jan./jun. 1999.

NÓVOA, A. Formação de professores e formação docente. In: Publicações Dom Quixote, 1997, p. 13-33.

OLIVEIRA, J. B. A. e Repetência, auto-estima e a reconquista da identidade. Dois Pontos, Belo Horizonte, v. 4, n. 35, p. 86-88, nov/dez 1997.

PATTO, M. H. S. 0 fracasso escolar como objeto de estudo: anotações sobre as características de um discurso. Cadernos de Pesquisa, São Paulo, n. 65, p. 72-77, maio 1988.

PERRENOUD, P. Práticas pedagógicas, profissão docente e formação: perspectivas sociológicas. 2. ed. Lisboa: Publicações Dom Quixote, 1997. 212 p.

Avaliação: da excelência à regulação das aprendizagens. Entre duas lógicas. Porto Alegre: Artes Médicas, 1999. 184 p.

ROMANELLI, 0. de 0. História da educação no Brasil. 21. ed. Petrópolis: Vozes, 1998. 268 p.

SILVA, R. N.; DAVIS, C. É proibido repetir. Estudos em Avaliação Educacional, São Paulo, n. 7, p. 5-44, 1993.

SILVA, R. N. et al. 0 descompromisso das políticas públicas com a qualidade do ensino. Cadernos de Pesquisa, São Paulo, n. 84, p. 5-16, fev. 1993. 
SPOSATI, A. Exclusão social e fracasso escolar. Em Aberto, Brasília, v. 17, n. 71, p. 21-32, jan. 2000.

TEIXEIRA, A. Educação no Brasil. São Paulo: Nacional, 1969. Cap. 11, p. 285-315.

Educação não é privilégio. 5. ed. Rio de Janeiro: Editora UFRJ, 1994. 231 p.

UNIVERSIDADE FEDERAL DE MINAS GERAIS. Faculdade de Educação. Grupo de Avaliação e Medidas Educacionais (GAME). Avaliação da implementação do projeto político-pedagógico Escola Plural. Belo Horizonte: UFMG/FaE/GAME, 2000. 142 p.

Recebido em 08.05.03

Aprovado em 10.02.04

Dília Maria Andrade Glória é doutoranda em Educação na Universidade Federal de Minas Gerais, é professora da Escola Fundamental do Centro Pedagógico da UFMG. Pesquisa atualmente as diferenças constitutivas das fratrias e sua relação com possíveis variações nas práticas e estratégias educativas familiares.

Leila de Alvarenga Mafra é doutora em Filosofia $(\mathrm{PhD})$ pela University of Pittsburgh, EUA. É professora do Programa de Pós-Graduação em Educação da PUC-Minas. Coordena um grupo de estudo e uma pesquisa que focaliza as relações entre os estabelecimentos escolares, a profissão docente e as trajetórias escolares. 